\section{First Nesting Record of the Leatherback Turtle, Dermochelys coriacea, in Japan}

\author{
NAOKI KAMEZAKI ${ }^{1,2 *}$, KATSUKI \\ $\mathrm{OKI}^{3}$, KOUJIRO MIZUNO ${ }^{1}$, TAICHIRO $^{2}$ \\ TOJI $^{1}$, AND OSAMU DOI ${ }^{4}$
}

${ }^{1}$ Sea Turtle Association of Japan, Nagaomotomachi 5-17-18-302, Hirakata, Osaka 573-0163, JAPAN

${ }^{2}$ Department of Ecosystem Studies, The University of Tokyo, Yayoi, Bunkyo, Tokyo 113-8657, JAPAN

${ }^{3}$ Amami Marine Exhibition Hall, Ohama 701-1, Naze, Kagoshima 894-0046, JAPAN ${ }^{4}$ Department of Biological Resources and Production, Faculty of Agriculture, Gifu University. Yanagido 1-1, Gifu 501-1193, JAPAN

Abstract: Nesting of the leatherback turtle Dermochelys coriacea in Japan was confirmed for the first time on the basis of two nests, each containing a clutch of eggs, found on Katoku Beach of Amami-oshima Island, central Ryukyus. There were no indications of development in eggs obtained from them. These nests were likely to have been made by the same individual.

Key words: leatherback turtle; Dermochelys coriacea; nesting; Ryukyu Archipelago; Japan

The leatherback turtle, Dermochelys coriacea, is the largest species of the extant marine turtles, and is known from almost the entire area of the Pacific, Indian, and Atlantic Oceans (Marquez, 1990). The major nesting grounds of the Pacific populations of this species are confined to a few small areas in the tropics, such as Trengganu in Malaysia (Fitter, 1961), northwestern New Guinea (Salm, 1981),

* Corresponding author. Tel: +81-72-864-0335; Fax: +81-72-864-0535

E-mail address: JCG03011@nifty.ne.jp (N. Kamezaki) the Solomon Islands (McKeown, 1977), and the western coast of central America (Pritchard and Trebbau, 1984). Although the leatherback is sometimes found in waters adjacent to Japan, nesting of this species has never been recorded with substantial evidence in Japan (Kamezaki, 1994). We report discovery of two nests of the leatherback turtle from a beach on Amami-oshima Island, southwestern Japan.

At Katoku Beach of Amami-oshima Island (Fig. 1), the emergence of one leatherback turtle was noticed by inhabitants at 14:00 on 28 June 2002. This individual, estimated to be approximately $1.8 \mathrm{~m}$ in straight carapace length on the basis of photographs (Fig. 2), dug an egg chamber, deposited eggs in it, and returned to the sea. Examination of the nest on 30 June 2002 yielded a total of 20 apparently normal eggs and 14 yokeless eggs. The mean diameter of the normal eggs was $53.0 \mathrm{~mm}$ ( $\mathrm{SD}=0.896$; range: $51.0-55.0 \mathrm{~mm}$ ).

On 11 July 2002, broad tracks and an indentation were found on the same beach, and a nest found just beneath the latter contained 66 apparently normal eggs and 18 yokeless eggs. The mean diameter of the normal eggs was $54.4 \mathrm{~mm}(\mathrm{SD}=0.964 ; 51.5-56.1 \mathrm{~mm})$.

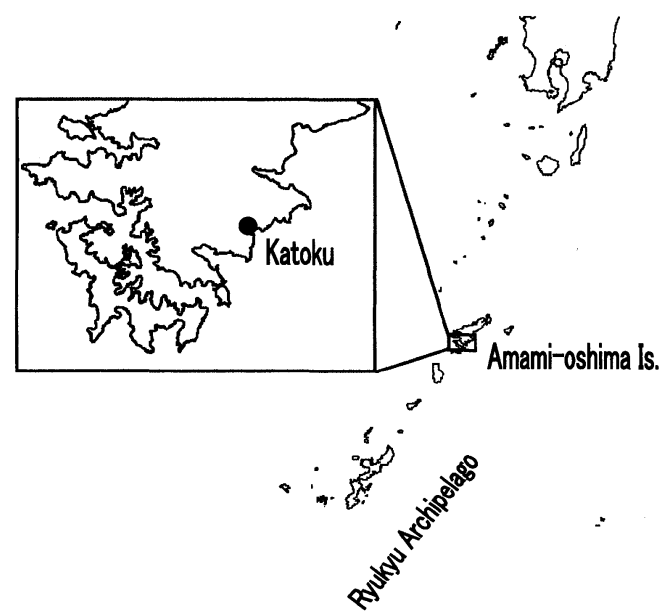

FIG. 1. Map showing location of the nesting site of the leatherback turtle, Dermochelys coriacea, on Amami-oshima Island, Ryukyu Archipelago, Japan. 


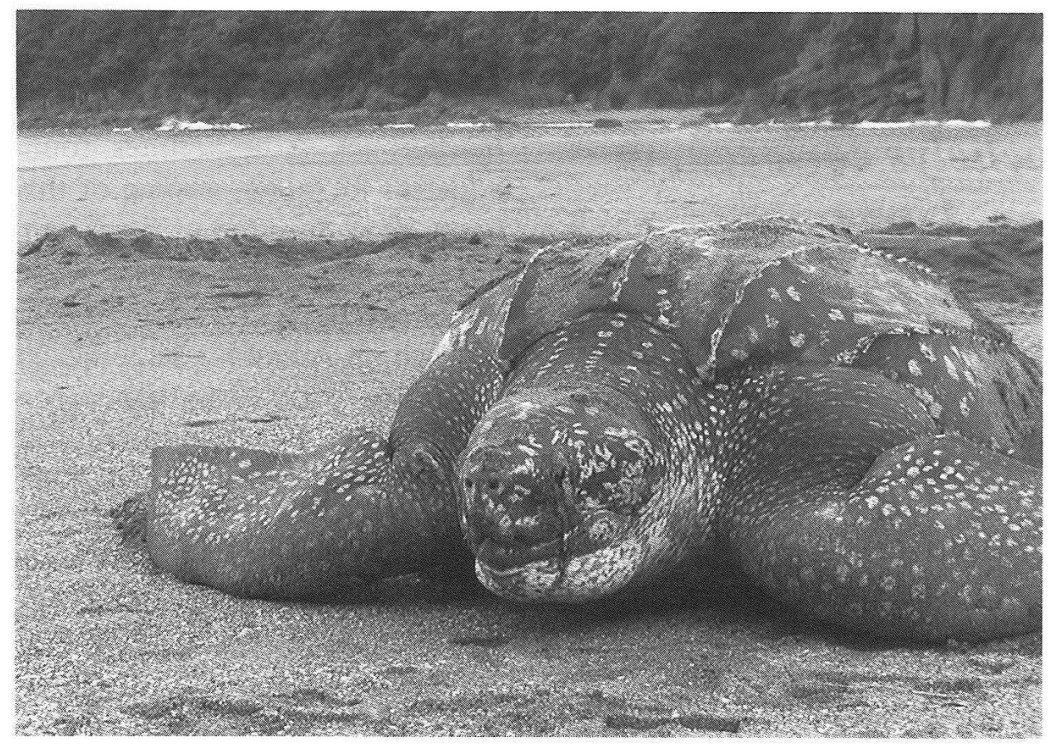

FIG. 2. The nesting leatherback turtle, Dermochelys coriacea, on Katoku Beach, Amami-oshima Island. Photographed on 28 July 2002 by Yoichi Baba.

The 20 apparently normal eggs from the first nest were moved to a styroform box for incubation under permission from the Fisheries Agency of Japan. However, no external signs of post-ovipositional development (Chan, 1989) were observed thereafter. One egg, opened on the eighth day, had a blastodisc, but with no indications of development from the ovipositional stage (Miller, 1985).

In the Ryukyu Archipelago, where Amamioshima Island is located, three species of marine turtles, the loggerhead turtle Caretta caretta, the green turtle Chelonia mydas, and the hawksbill turtle Eretmochelys imbricata, are known to nest (Kamezaki, 1989). One case of nesting of the leatherback turtle was once mentioned by an inhabitant on another island (Zamamijima Island of the Okinawa Group) but without any substantial evidence (H. Ota, private communication). The observation made on 28 June 2002 thus offers the first confirmed record of nesting of this species in Japan.

The number of eggs found in the first nest (34 including the abnormal eggs) was much smaller than the ordinary size of a nest clutch in the leatherback turtle (Marquez, 1990). This, along with the extreme softness of the sand covering that nest, suggests that a large proportion of eggs originally laid therein had already been poached by someone when the nest was examined by us on 30 June.

With respect to the second nest, the emerging female was not observed. Even so, however, there is no doubt that this nest also belonged to the leatherback turtle, because size of its eggs $(51.0-56.1 \mathrm{~mm})$ was much larger than that of eggs of the other marine turtles nesting in the Ryukyus (34-46 mm: Kamezaki, 1987), and fell within the known range of egg sizes in the leatherback turtle (45.6-59.2 mm: Marquez, 1990). These two nests are likely to have been made by the same individual, considering that they were found on the same beach with an interval (13 days) close to the known renesting intervals in this species (9-11 days: Pritchard and Trebbau, 1984).

\section{ACKNOWLEDGMENTS}

We thank Dr. Nel Beaumont and Dr. Yoshimasa Matsuzawa for critically reading the manuscript, and Yoichi Baba, Mitsuhiro Oki, Hidetoshi Ota, and Takashi Noma for 
providing relevant information and photographs.

\section{LITERATURE CITED}

CHAN, E. 1989. White spot development, incubation and hatching success of leatherback turtle (Dermochelys coriacea) eggs from Rantau Abang, Malaysia. Copeia 1989 (1): 42-47.

FiTTER, R. 1961. The leathery turtle or luth. Oryx. 6 (2): $116-125$.

KAMEZAKI, N. 1987. The nesting of sea turtles in the Yaeyama Islands. p. 367-389. In: Yaeyama Bunka Ronsou. Project Group for Commemorating the Centennial of the Birth of Kishaba Eijyun. Ishigaki, Okinawa. (in Japanese)

KAMEZAKI, N. 1989. The nesting of sea turtles in the Ryukyu Archipelago and Taiwan main Islands. p. 342-348. In: M. Matsui, T. Hikida, and R. C. Goris (eds.), Current Herpetology in East Asia. Herpetological Society of Japan, Kyoto.

KAMEZAKI, N. 1994. Leatherback turtle. p. 479491. In: Basic Data for Endangered Species of Wild Aquatic Animals in Japan (1). Fisheries
Agency of Japan, Tokyo. (in Japanese)

MARQUEZ, M. R. 1990. FAO Species Catalogue: Sea Turtles of the World. FAO Fisheries Synopsis, Vol. 11, No. 125. Rome, FAO. 81 p.

MCKEOWN, A. 1977. Marine turtles of the Solomon Islands. Ministry of Natural Resources, Fisheries Division, Honiara. 45 p.

MILLER, J. D. 1985. Embryology of marine turtles. p. 270-328. In: C. Gans, F. Billet, and P. F. A. Maderson (eds.), Biology of the Reptilia, Vol. 14. Wiley-Interscience, New York.

PRITChard, P. C. H. AND P. TrebBaU. 1984. The Turtles of Venezuela. Society for the Study of Amphibians and Reptiles, and Fundacion de Internados Rulales, Caracas, Venezuela. 403 p., 47 pls. \& 16 maps.

SALM, R. V. 1981. Trengganu meets competition: does Irian Jaya harbour southeast Asia's densest leatherback nesting beaches? Conservation Indonesia (Newsletter, World Wild Found Indonesia) 5: 18-19.

Accepted: 28 December 2002 